\title{
FUNDAMENTS OF VIRTUAL ORGANIZATION E-CONTRACTING
}

\author{
Lai Xu, Paul de Vrieze \\ CSIRO ICT Center, AUSTRALIA,Lai.Xu@csiro.au \\ Paul@adaptivity.nl
}

\begin{abstract}
E-contracts have been broadly used to improve business-to-business collaboration. Different e-contracting activities have been identified to support e-contract establishment and e-contract fulfillment. In virtual organization domain, there exist different types of virtual organizations. Each of them has different purposes, missions and goals. As an important step in a virtual organization creation process, how e-contracting activities work in different types virtual organization is still blurred. In this article we examine specific requirements of e-contracting activities for different types of virtual organization.
\end{abstract}

\section{INTRODUCTION}

E-contracting has been recognized as an important phase of the Virtual Organization (VO) creation process (Camarinha-Matos et al., 2005). General requirements and needs of e-contract and e-contracting platforms have been described in (CamarinhaMatos \& Oliveria, 2005). For different purposes, missions and goals, virtual organizations can be further classified into business oriented virtual organizations and non-business oriented virtual organizations, such as incident management teams and disaster rescue teams.

E-contracts and processes for e-contracting among different virtual organizations certainly have different characteristics. A business oriented virtual organization normally has a specific goal, i.e. achieving maximum profit for a common interest between business partners. To achieve the goal, the business process is optimized, specified and agreed upon by all involved partners. The contract between business partners has specified obligations, permissions and prohibitions for each partner; business activities that are expected to occur and sanctions for any deviation from the prescribed behavior. The contract thus clearly defines the business process. The representation/model of the contract and the monitoring for contract violations are very important for business oriented virtual organizations. On the other hand, a contract between parties involved in an incident management team certainly cannot involve all details of the management process. What, why, and how an incident happens can by definition not be predicted well in advance. Therefore, the contract mainly contains guidelines which are much more abstract than the content in a business process contract. After getting more information, different scenarios will appear. The monitoring of the contract execution and performance of each partner is more important for this type of virtual organization.

In this paper, we will present the specific requirements for e-contracts and econtracting for different types of virtual organization.

$\mathrm{Xu}$, L., de Vricze, P., 2007, in IFIP International Federation for Information Processing, Volume 243, Establishing the Foundation of Collaborative Networks; eds. Camarinha-Matos, L., Afsarmanesh, H., Novais, P., Analide, C.; (Boston: Springer), pp. 209-216. 


\section{VIRTUAL ORGANIZATION AND E-CONTRACTING}

Different kinds of virtual organizations cause different requirements for different econtracting processes. In this section, we will further explain relations between four main collaboration modalities and electronic contracting.

Four main collaboration modalities have been identified (Camarinha-Matos et al., 2005), namely: Collaborative business process model, Project model, Problem solving model and Ad-hoc collaboration model. A collaborative business process model can be defined as a set of heterogeneous activities normally distributed in cross-organizational sub-processes. Standards and technologies permit business partners to exchange information, collaborate, and carry out business transaction in a pervasive network environment. Business process collaboration predefines a set of activities or processes of organization through networks to accomplish an explicitly shared business goal. A car insurance case can be seen as an example of collaborative business process. In this car insurance case, garages and a call center will collaborate with a car insurance company to provide the service of repairing the damaged cars of insurants (Xu \& Brinkkemper, 2005).

A collaborative project model is defined as the support for multi-projects towards the definition of a work break down structure, composed of sub-projects, work packages, tasks and activities and the support for the human resource management where human resources belong to multi-organizations. The crucial issue for a collaboration project model is to optimize resource allocation, such as changing the planning and rescheduling of resources according to situational factors. For example, a European research project normally involves many project partners. A coordinator has to be appointed to report the process to European research consortia. Each project partner works on sub-projects under a big umbrella project.

In a collaborative problem solving model, a mediator is needed to collect and evaluate contributions. Collaboration measurement and reward provides identification of value metrics, rewarding of expert contributing decisively towards the roadmap's goal achievement. An example of this class of collaborations is the case of when a manufacturing company would like to reduce the failure rate of its production process. In order to do this the manufacturer will ask other members within the virtual organization, which have equal or similar production process. Different suggestions will be collected and evaluated for using (Camarinha-Matos et al., 2005).

The ad-hoc collaboration model is useful when big organizations, not used to tightly collaborate with one another, are required to join their efforts in order to rapidly give a quick response to an external request. An example is the process of responding to an airplane crash. A Belgian Hercules military airplane crashed at army airbase in Eindhoven, The Netherlands, while carrying 37 members of the Royal Dutch Army brass band and a crew of four. The initial crash caused the passengers or crew no serious harm. However, due to the kerosene fire that followed in combination with errors made during the disaster response 34 persons died and the remaining 7 were seriously wounded. The rescue team was composed of partners such as the air-traffic control, the airbase fire department, the Eindhoven fire department, central post for ambulances and national emergency center. The disaster organization failed due to miscommunications, inefficient collaboration between the airbase fire department and the Eindhoven fire department and insufficient resources (human and material) to cope with the disaster (Abbink et al., 2004). The ad-hoc 
collaboration model is not like a collaborative business process model where a clear process can be defined in advance. To make involved partners work together efficiently is crucial.

\subsection{E-contracting and E-contracts}

Although there exist different descriptions for the e-contracting process (Milosevic and Bond,1995) (Goodchild, Herring \& Milosevic, 2000), the general e-contracting process includes two stages: contract establishment (contract formation) and contract enactment (contract performance or contract fulfillment) (Xu, 2004) (Angelov, 2005). E-contracting processes and all activities belonging to different e-contracting processes are shown in Figure 1. E-contracting activities such as identifying, checking and validating of contractual parties, negotiation and contract validation, are included in the stage of contract establishment. The contract enactment is further separated into two phases: fulfillment and post-contractual activities (Angelov, 2005). Monitoring of contract fulfillment belongs to the contract fulfillment phase while contract enforcement and compensation may be involved in both the contract fulfillment and post-contractual activities.

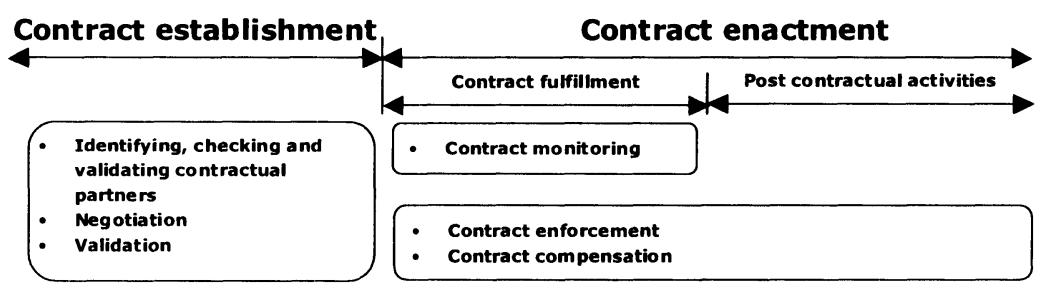

Figure 1- E-contracting process and activities

Electronic contracting research focuses on negotiation of the terms and conditions of the contract and the monitoring of contract performance (Lee, 1998). Contract negotiation is described as the process in which contractual parties come to a mutual agreement on the contract content. Contract negotiation can be performed with or without the help of a third party. There are three critical aspects in the negotiation of a contract (Burgwinkel, 2002). First, the subject of the contract needs to be defined exactly. Second, the legal validity must be formulated. Third, the price and conditions of each item need to be negotiated in relation to the quality of deliverables and the quality of services and in relation to the legal terms.

Contract monitoring is the process of observing the activities performed by the parties, knowing the state of contract execution and detecting contract violations. It is important for the contractual parties to monitor the performance of the other collaborating parties, especially if the transactions are business critical. This process aims to guarantee that the performed processes are in accordance with the agreed contract. The monitoring of contract performance can be split into two parts divided by the occurrence of an anomalous action (Xu \& Jeusfeld, 2003) (Xu, 2004). The part preceding the occurrence of anomalous actions is called the proactive monitoring of contract performance. The part following it is called reactive monitoring of contract performance. The contract monitoring process and activities can be found from Figure 2. In the pro-active monitoring stage, anomalous actions can be avoided and anticipated before contract violation occurrence. In the reactive monitoring stage, anomalous actions can be detected; the partners who are responsible for the 
violations need to be identified. The relevant partner also needs to be compensated, and unsolvable disputes stored for future human-involved resolution.

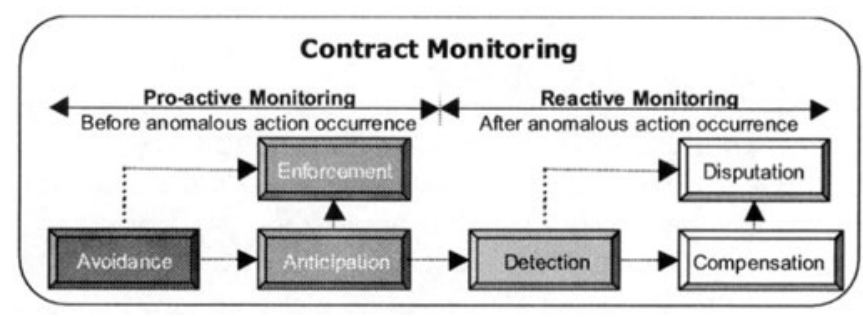

Figure 2 - Contract monitoring processes

Contract enforcement is the process of persuading the noncompliant party to perform corrective actions. The contract enforcement can be done in three ways: pro-actively (through constraints provided in the contract), reactively (via auxiliary corrective measures aiming at minimizing the deviations from the contract), and post-contractually (by constraining future activities of that company in this domain) (Angelov, 2005).

To fulfill contracts automatically, contract model/representation brings innovations in collaborative business processes. Existing contract models, such as the e-contracting logic model (Lee, 1998), aim to improve both expressiveness and inferential capabilities of the contracts. The model proposed in (Weigand \& $\mathrm{Xu}$, 2001) focuses on task allocations and process co-ordinations. The pro-active monitoring contract model $(\mathrm{Xu}, 2003,2004)$ and multi-party contract model $(\mathrm{Xu}$, 2004b) provide contract models for different objectives. These models are representing trading contracts. To fulfill e-contracts over networks, a contract template is a predefined contract that can be used as a basis for a new contract. It defines the document structure of the contract and has predefined clauses and legal terms (Angelov and Grefen, 2001). To establish contract templates is one possible procedure for managing model contracts.

In order to format and fulfill contracts electronically, e-contracts have to be managed. There are different views at contract management. From a contract platform perspective, contract management includes

- a single repository for all contracts, related documents and information to users,

- searching, reporting and reusing capabilities to access all information in contracts and attachments,

- the ability to track and monitor for each contractual partner key performance indicators (KPIs) and performance over the contract execution and use this information to target improvement actions and to determine preferred status, rankings, etc.,

- maintenance of different versions of contracts, automatically reconcile changes to terms and clause language, and compare different versions,

- clause and template library to capture standard and alternate clauses along with guidelines, and

- alerts and reminders to inform contract partners of any upcoming dates, events and milestones. 
From one contractual party point of view, both its supplier and customer contracts need to be managed. Moreover, the interrelation between these internal and external obligations, rights, and penalties must be synchronized.

In this section, four collaboration modalities, contract processes, contract negotiation, contract monitoring, contract enforcement, contract model and contract management have been reviewed. The specific needs and requirements of e-contracting for different collaboration modalities will be provided in the next section.

\section{E-CONTRACTING FOR VIRTUAL ORGANIZATION}

From the aspects of contract negotiation, contract monitoring, contract enforcement, contract model/representation and contract management, we will analyze e-contracting requirements for each collaborative modality of virtual organizations.

\subsection{E-Contract for Collaborative Business Process model}

After identifying and specifying a new collaboration opportunity, a new virtual organization will be created in response. Contracts or cooperation agreements are defined among the selected partners.

To negotiate the contract, not only the subject of the contract, the terms and conditions of the contract and collaboration business process specification need to be defined exactly, but also representation of the e-contact, such as, it must be decided to specify multi-party involved business collaboration by using a multiparty e-contract or multiple bilateral e-contracts, whether a XML-based contract specification is a suitable representation, etc. The contract is eventually signed after the negotiations are complete.

When the collaboration business process contract is executed, there are three monitoring requirements:

- quality of performance of each party,

- current state of the contract execution,

- contract violation detection.

When collaboration business process is a combination of choreographed business transactions, the quality of each party performance should not be a big concern, because a business transaction is an atomic unit of work that can result in either a success or a failure. If any party fails to perform the transaction, it will be detect as a contract violation. If pro-active monitoring is required, following items need also be included,

- computing what is expected in any state of the business execution

- detecting imminent violations

- reminding the relevant parties to fulfill their obligations

The current state of the contract execution should be monitored in both pro-active and reactive monitoring.

The result of pro-active and reactive monitoring can trigger contract pro-active and reactive enforcement clauses in the contract respectively. Detecting contract violation is certainly important for a collaboration business process virtual organization. Sanctions can be established as a consequence of detection of a contract violation. Furthermore, finding the responsible party or parties for a contract 
violation is crucial for a collaboration business process virtual organization. All three ways contract enforcement can be useful for a collaboration business process virtual organization. The way of contract monitoring and contract enforcement is performed, such as whether pro-active monitoring or pro-active enforcement is used, will be specified in different constraints. These constrains and calculation of constrains will eventually determine the model/representation of the e-contract.

Contract management, both from a contract platform view and from the point of view of a single contractual party is important for this type of virtual organization.

\subsection{E-Contract for Collaborative Project Model}

In a collaborative project virtual organization, a coordinator and several project partners are involved and they work together to finish a big project, which no single project partner can finish by itself. Figure 3 shows an example of the contracts between involved members of the virtual organization.

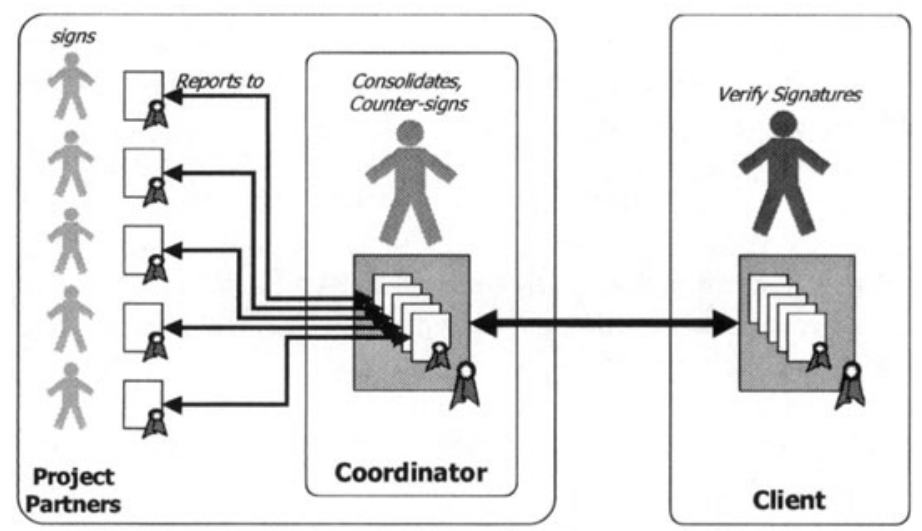

Figure 3 - Contracts in a collaborative project virtual organization

In a collaborative project virtual organization, work can be broken down into multi-projects, tasks or activities, therefore the progress of each sub-project cannot be estimated exactly. Certain parts of contracts or certain parameters should be renegotiable. How much is allowed to be monitored is thus important for the collaborative project virtual organization. If pro-active contract monitoring is allowed, the accurate process of virtual organization can be known better, the re-planning and re-scheduling can take place properly.

The results of monitoring contract execution can bring great value to this type of virtual organization. Quality of each partner's performance is useful for future collaboration. Current state of contract execution is the basis of the pro-active contract monitoring. Early detection of contract violations can contribute to the whole process scheduling. In short, the new planning or scheduling can be changed according the results of the pro-active and reactive monitoring.

Contract management is critical for the collaborative project virtual organization. Re-planning, re-scheduling or re-negotiating is often happening in the collaborative project virtual organizations. Different versions of the contract need to be maintained; changes of terms and clauses need to be reconciled; and alerts and reminders should inform involved partners of any upcoming dates and events. 


\subsection{E-Contracts for Problem Solving Model}

In a problem solving virtual organization, a mediator has been assigned. Therefore a central contract platform can be applied in a problem solving virtual organization. It benefits contract negotiation, monitoring and management.

A problem solving virtual organization can only define the scope of the problem, which needs to be solved. After getting experts/contributors for the problems, the content of the contracts needs to be more abstract than going to trivial details. In a problem solving virtual organization, contract negotiation should be relatively easy, even a take-it-or-leave-it contract can be used in this type of virtual organization. An import task for the mediator is to monitor the quality of performance for each partner. The mediator should collect and evaluate contributions from each partner. Mechanisms of collaboration measurement and reward need to be designed. The contract model/representation should facilitate the collection of contributions of each partner.

\subsection{E-Contracts for Ad-hoc Collaboration Model}

In section 2, we have provided an example for ad-hoc collaboration model virtual organization. Giving a quick response to an unforeseen incident such as a disaster is the characteristic of the ad-hoc collaboration virtual organization. Because the collaboration activities have to rapidly respond to an unknown event, the content of the contracts normally does not have to be negotiated much. The responsibilities or obligations normally have been written in certain documents, e.g. a disaster prevention plan. The way to deal with one specific incident won't be specified. Therefore the content of the contract stays on a meta-level. For contracting in such situation mapping the as-is situation and the to-be scenario with the prevention plan into the procedures will help all partners to deal with confusions, to know exactly what they need to perform. Therefore, contact model/representation and contract monitoring are important. It is a big challenge to design an e-contracting solution that can use contextual information to translate the abstract contract into concrete processes during contract execution.

Table 1 provides summary information of important e-contracting activities for four collaboration model of virtual organizations.

Table 1 - Summary of important e-contracting activities

\begin{tabular}{|c|c|c|c|c|c|}
\hline & $\begin{array}{c}\text { Collaborative } \\
\text { Business } \\
\text { Process VO }\end{array}$ & $\begin{array}{c}\text { Collaborative } \\
\text { Project VO }\end{array}$ & $\begin{array}{c}\text { Collaborative } \\
\text { Problem } \\
\text { Solving VO }\end{array}$ & $\begin{array}{c}\text { Ad-hoc } \\
\text { Collaboration } \\
\text { VO }\end{array}$ \\
\hline \multicolumn{2}{|c|}{ Contract negotiation } & + & ++ & + & \\
\hline \multicolumn{2}{|c|}{$\begin{array}{c}\text { Contract } \\
\text { model/representation }\end{array}$} & ++ & + & + & +++ \\
\hline \multirow{3}{*}{ 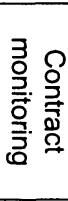 } & $\begin{array}{c}\text { Quality of } \\
\text { performance }\end{array}$ & & & ++ & +++ \\
\hline & $\begin{array}{l}\text { Current state } \\
\text { of contract } \\
\text { execution }\end{array}$ & ++ & + & & +++ \\
\hline & Violation & $\begin{array}{c}+ \\
+\end{array}$ & + & & ++ \\
\hline \multicolumn{2}{|c|}{$\begin{array}{c}\text { Contract } \\
\text { enforcement }\end{array}$} & ++ & + & & \\
\hline \multicolumn{2}{|c|}{$\begin{array}{c}\text { Contract } \\
\text { management }\end{array}$} & + & ++ & & ++ \\
\hline
\end{tabular}

The numbers of "+" represent the importance. 


\section{CONCLUSIONS}

In collaborative business process virtual organizations, e-contracting is more close to the e-contracting in business-to-business (b2b) collaboration. Although there are still enough challenges in the area, most current research results of e-contracting are mainly in this area. The result of e-contracting research from $b 2 b$ collaboration e-contracting can be also adopted and be adjusted for collaborative project virtual organizations and collaborative problem solving virtual organizations.

For a collaborative project virtual organization, multiple partners can be involved, in this case the contract with multiple partners can be broken down into multiple bilateral contracts. Therefore, the current result of e-contracting research can still be well applied.

In a collaborative problem solving model of visual organizations, current research on e-contracting can be adopted and adjusted easily. Collection and evaluation of performance quality of each partner are important issues in this area.

However, the issues of ad-hoc collaborative e-contracting certainly are a big challenge in the e-contracting area. To map a meta-level contract/agreement into specific processes during a contract execution stage, many issues need to be solved. Method Engineering is one of the areas which should look at for finding a solution. In short, e-contracting is a still relative new research area. Still many challenges remain.

\section{REFERENCES}

1. Angelov, S. (2005) Foundations of B2B Electronic Contracting, Technische Universiteit Eindhoven.

2. Angelov, S. and Grefen, P., B2B eContract Handling - A survey of Projects, Papers and standards. University Twente, CTIT Technical Reports, 2001.

3. Burgwinkel, D. (2002) Decision Support in Electronic Contract Management. Procedding of the Interntaional Conference on Decision Marking and Decision support in the Internet Age DSIAGE.

4. Camarinha-Matos, L. M.; Silveri I.; Afsarmanesh H.; Oliveira A.I. Towards a Framework for Creation of Dynamic Virtual Organizations. In Collaborative Networks and their Breeding Environments, (PRO-VE'05) Springer, Valencia, Spain, 26-28 Sep 2005.

5. Camarinha-Matos, Luís and Oliveira, A. Contract negotiation wizard for VO creation. In: DET'06 3rd International CIRP Conference in Digital Enterprise Technology, 18-20 Sept 2006

6. Goodchild, A., Herring, C. and Milosevic, Z. (2000) Business contracts for B2B, in Ludwig, H., Hoffner, Y., Bussler, C., and Bichler, M. (eds.) Proceedings of the CAISE*00 Workshop on Infrastructure for Dynamic Business-to-Business Service Outsourcing, ISDO '00, Stockholm, June 5-6, 2000 CEUR-WS.org.

7. Lee, R. (1998) Towards Open Electronic Contracting, EM - Electronic Markets, 8(3) pp.3-8.

8. Milosevic, Z. and Bond, A. (1995) Electronic commerce on the Internet: what is still missing? Proceedings of the 5th Annual Conference of the Internet Society, INET'95, Honolulu, Hawaii.

9. Weigand, H. and Xu, L. (2001) Contracts in e-commerce. In 9th IFIP 2.6 Working Conference on Database Semantic Issues in E-Commerce Systems (DS-9).

10. Xu, L. and Jeusfeld, M. A. (2003) Pro-active Monitoring of Electronic Contracts , In: The 15th Conference On Advanced Information Systems Engineering (CAiSE 2003). Lecture Notes of Computer Science Volume 2681/2003, Springer-Verlag.

11. Xu, L. (2004) Monitoring Multi-party Contracts for E-business, Ph.D. thesis, University of Tilburg.

12. Xu, L. (2004b) A Multi-party Contract Model , In: ACM SIGecom Exchanges Vol. 5, No.1, pages 13-23.

13. $\mathrm{Xu}, \mathrm{L}$. and Brinkkemper, S., Modelling Multi-party Web-based Business Collaborations, In: Proceedings of IFIP WG 2.12 \& WG 12.4 Workshop on Web Semantics (SWWS 05). Lecture Notes in Computer Science Volume 3762, Springer Verlag, 2005. 